\title{
Transport of Radioactive Material by Alpha Recoil
}

\section{May 2005}

\section{Prepared by}

\author{
A. S. Icenhour
}




\section{DOCUMENT AVAILABILITY}

Reports produced after January 1, 1996, are generally available free via the U.S. Department of Energy (DOE) Information Bridge:

Web site: http://www.osti.gov/bridge

Reports produced before January 1, 1996, may be purchased by members of the public from the following source:

National Technical Information Service

5285 Port Royal Road

Springfield, VA 22161

Telephone: 703-605-6000 (1-800-553-6847)

TDD: $703-487-4639$

Fax: 703-605-6900

E-mail: info@ntis.fedworld.gov

Web site: http://www.ntis.gov/support/ordernowabout.htm

Reports are available to DOE employees, DOE contractors, Energy Technology Data Exchange (ETDE) representatives, and International Nuclear Information System (INIS) representatives from the following source:

Office of Scientific and Technical Information

P.O. Box 62

Oak Ridge, TN 37831

Telephone: 865-576-8401

Fax: 865-576-5728

E-mail: reports@adonis.osti.gov

Web site: $\mathrm{http}: / / w w w . o s t i . g o v /$ contact.html

This report was prepared as an account of work sponsored by an agency of the United States Government. Neither the United States government nor any agency thereof, nor any of their employees, makes any warranty, express or implied, or assumes any legal liability or responsibility for the accuracy, completeness, or usefulness of any information, apparatus, product, or process disclosed, or represents that its use would not infringe privately owned rights. Reference herein to any specific commercial product, process, or service by trade name, trademark, manufacturer, or otherwise, does not necessarily constitute or imply its endorsement, recommendation, or favoring by the United States Government or any agency thereof. The views and opinions of authors expressed herein do not necessarily state or reflect those of the United States Government or any agency thereof. 
ORNL/TM-2005/22

Nuclear Science and Technology Division

TRANSPORT OF RADIOACTIVE MATERIAL BY ALPHA RECOIL

A. S. Icenhour

Date Published: May 2005

Prepared by OAK RIDGE NATIONAL LABORATORY

P.O. Box 2008

Oak Ridge, Tennessee 37831-6283

managed by

UT-Battelle, LLC

for the

U.S. DEPARTMENT OF ENERGY

under contract DE-AC05-00OR22725 



\section{CONTENTS}

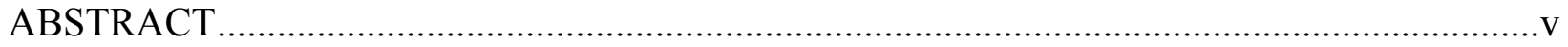

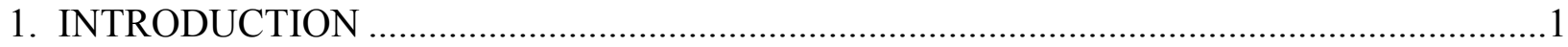

2. REVIEW OF REPORTED ALPHA-RECOIL PHENOMENA ...........................................

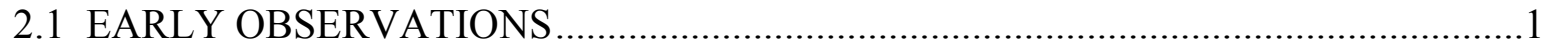

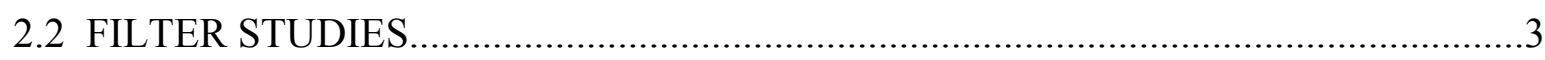

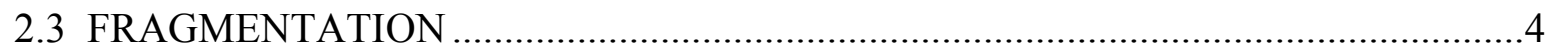

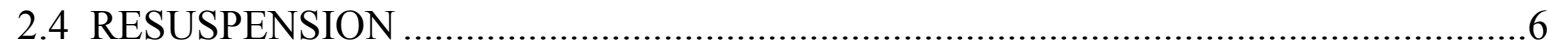

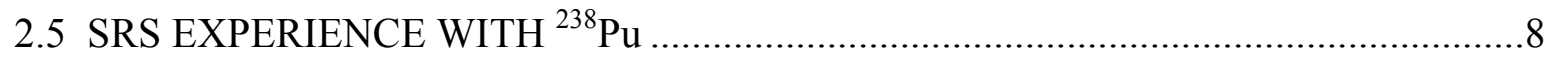

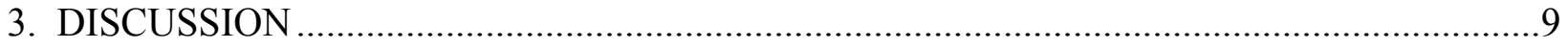

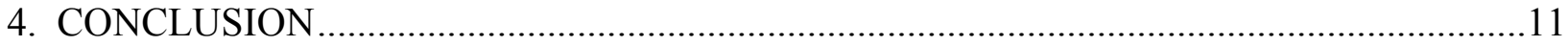

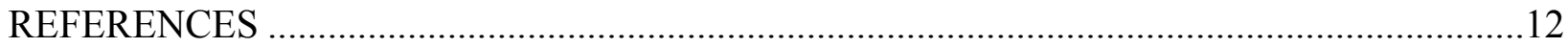

APPENDIX. BIBLIOGRAPHY OF SOURCES REVIEWED …............................................. 15 



\begin{abstract}
The movement of high-specific-activity radioactive particles (i.e., alpha recoil) has been observed and studied since the early 1900s. These studies have been motivated by concerns about containment of radioactivity and the protection of human health. Additionally, studies have investigated the potential advantage of alpha recoil to effect separations of various isotopes. This report provides a review of the observations and results of a number of the studies.
\end{abstract}





\section{INTRODUCTION}

The movement of high-specific-activity particles as a result of alpha recoil is a phenomenon that has been observed and studied since the early 1900s. Such phenomena have direct implications for the transport and dispersal of radioactive materials. These studies have been motivated by concerns about the containment of radioactive material and the increased potential for uptake of material by humans. Additionally, studies have investigated the potential advantage of alpha recoil to effect separations of isotopes. This report reviews the observations and studies performed to date, analyzes the results of these studies in the context of the release and transport of radioactive material, and describes the types of parameters that have been used to quantify movement by alpha recoil.

\section{REVIEW OF REPORTED ALPHA-RECOIL PHENOMENA}

Alpha-recoil phenomena have been studied for a variety of reasons. These studies can be divided into several categories: early observations, filter studies, fragmentation, and resuspension. These areas are discussed in the following subsections. Additionally, the experience with ${ }^{238} \mathrm{Pu}$ at the Savannah River Site (SRS) is described.

\subsection{EARLY OBSERVATIONS}

One of the earliest published descriptions of recoil transport was by Makower and Russ (1910), who noted that Radium B $\left({ }^{214} \mathrm{~Pb}\right)$ appeared to be transported by the Radium C $\left({ }^{214} \mathrm{Bi}\right)$ recoil atom. (Figure 1 depicts the decay scheme for these ${ }^{222} \mathrm{Rn}$ progeny.) Such an event was later termed "aggregate recoil" by Lawson (1919) and others. In the case of "aggregate recoil," the recoiling atom has sufficient energy to move additional particles that are attached to it (i.e., the aggregates). Lawson (1924) attributes anomalous counting results for polonium to aggregate recoil, whereby the movement and electrostatic attraction of charged recoil nuclei (and associated aggregates) to aluminum filters changed the measured counts. He observed that such anomalies should decrease with time as the number of aggregates is reduced (either by fragmentation of the aggregate or by transport of particles away from the surface being counted). 
Harrington (1928) provided experimental evidence for the formation of particulate aggregates in radon gas. He suggested that some of the aggregates that settle out may be suspended back into the gas by alpha recoil. However, this idea was not explored further. Harrington and Gratias (1931), who performed experiments on mixtures of radon gas and polar molecules, found that the presence of polar molecules favored, and might be essential in, the formation of large aggregates.

Rutherford, Chadwick, and Ellis (1930) described the aggregate-recoil phenomenon in terms of separations of atoms. In this case, the daughter of a decaying atom will recoil from a radioactive deposit and, because it is positively charged, can be collected on a negative electrode. This event should thereby effect a separation of a pure daughter product from the deposit. However, activity from the parent is often found with the "separated" daughter, showing that some atoms from the deposit were transferred along with the recoiling daughter.

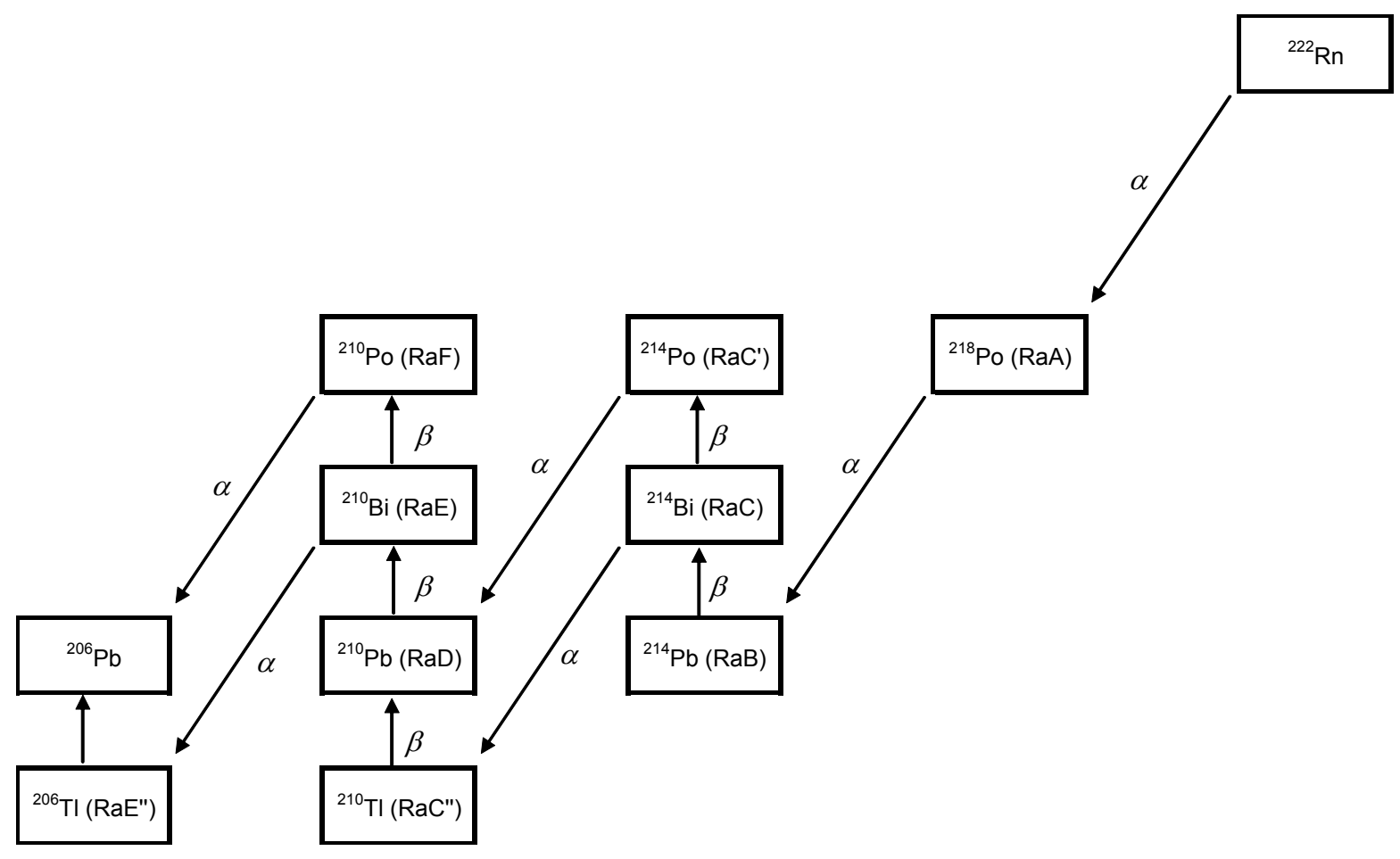

Fig. 1. Major decay mode of ${ }^{222} \mathrm{Rn}$ and its daughters. 


\subsection{FILTER STUDIES}

A number of studies have been performed with respect to the transport of alpha-active particles through filters. The distribution of ${ }^{239} \mathrm{Pu}$ in a high-efficiency particulate air (HEPA) filter was studied using autoradiography by Ryan, McDowell, and Case (1977). They found that the plutonium was transported through the filter by aggregate alpha recoil (i.e., aggregate recoil particles, which are produced from larger particles, are reentrained in the airflow and then deposit deeper in the filter).

Ryan, Skrable, and Chabot (1975) studied the aggregate recoil of ${ }^{212} \mathrm{~Pb}$ particles through glass fiber filters. They state that the recoil energy of the ${ }^{212} \mathrm{~Pb}$ daughter is about $100 \mathrm{keV}$, which is about $10^{5}$ times the chemical bond energy of lead atoms. Consequently, to conserve momentum, a large number of parent atoms must recoil with the daughter nucleus. Their work showed that aggregate recoil "can increase the effective penetration of aggregate recoil particles through glass fiber filters." They found penetration of particles through multiple filters arranged in series. An aggregate particle may be initially attached to a filter. However, through subsequent decay, a portion of the particle may become detached (i.e., a new, smaller aggregate is formed) and move through the filter. Such phenomena can cause movement of particles through multiple filters. Ryan, Skrable, and Chabot identified two key parameters that influence the aggregate-recoil phenomenon - the specific activity of the alpha-emitting material and the number of active atoms per aggregate. The size distribution of the recoiling particles in terms of the number of active atoms per particle is useful in evaluating the hazard from recoil transport. Measurements for aggregate recoil particles of ${ }^{212} \mathrm{~Pb}$ resulted in a size distribution of about 1000 atoms per particle, with a diameter of about $3 \mu \mathrm{m}$ [McDowell, Seeley, and Ryan (1976), a publication that cites thesis results by J. A. Vento].

McDowell, Seeley, and Ryan (1977) have shown that alpha-emitting particulates penetrate HEPA filters much more easily than do nonradioactive or beta-gamma-emitting aerosols. They have observed such phenomena with ${ }^{212} \mathrm{~Pb},{ }^{253} \mathrm{Es},{ }^{238} \mathrm{Pu}$, and ${ }^{239} \mathrm{Pu}$. Beta-gamma-emitting materials did not migrate through the filters. However, when mixed with alpha-emitting material, the beta-gamma activity did migrate. This migration occurred by the dislodging of small active particles from the surface of an alphaactive material (by alpha recoil). Such dislodging is repeated, and the radioactivity then migrates. Oxide, nitrate, and plated metal forms of sources all were found to effectively generate recoil particles.

In a more detailed report of their work, McDowell, Seeley, and Ryan (1976) developed a simple mathematical model for the transport of alpha-recoil aggregates through filters. The basic equation governing the release of particles from a filter is 


$$
\frac{d N_{s}}{d t}=-\left(K_{\mathrm{s}}+\lambda\right) N_{\mathrm{s}}(t)
$$

where

$$
\begin{aligned}
& N_{\mathrm{s}}(t)=\text { the number of active atoms on a source, } \\
& K_{\mathrm{s}}=\text { the rate constant for transfer of atoms by the aggregate-recoil process, and } \\
& \lambda \quad=\text { the radioactive decay constant. }
\end{aligned}
$$

The rate of release of atoms from the source by aggregate recoil is then given by the product $K_{\mathrm{s}} N_{\mathrm{s}}$. Note that this equation was developed for transport through filters and that a similar equation could be written for each filter stage (i.e., with the release rate from one stage becoming the deposition rate in the next). However, the basic equation is applicable for release of particles from a source. Values of the transfer rate constant were reported for three radioisotopes: ${ }^{238} \mathrm{Pu}\left(2.44 \times 10^{-6} \mathrm{day}^{-1}\right),{ }^{253} \mathrm{Es}\left(1.16 \times 10^{-6} \mathrm{~h}^{-1}\right)$, and ${ }^{212} \mathrm{~Pb}\left(4.17 \times 10^{-8} \mathrm{~h}^{-1}\right)$. (Note that ${ }^{212} \mathrm{~Pb}$ decays by beta emission, however, its daughters ${ }^{212} \mathrm{Bi}$ and ${ }^{212} \mathrm{Po}$ decay rapidly by alpha emission.)

\subsection{FRAGMENTATION}

Fragmentation of high-specific-activity particles has been a concern because smaller particles can be more easily taken up by the body. Consequently, the fragmentation of particles as a result of recoil has been the subject of several studies. Fleischer (1975), and Fleischer and Raabe (1977) examined the solubility of $\mathrm{PuO}_{2}$ in simulated lung fluid. Here solubility refers to the "conversion of plutonium in the extremely insoluble particles of $\mathrm{PuO}_{2}$ to more dispersed forms." These authors observed that ${ }^{238} \mathrm{PuO}_{2}$ dissolves at a rate that is about 200 times faster than ${ }^{239} \mathrm{PuO}_{2}$, which has a much lower specific activity (17 $\mathrm{Ci} / \mathrm{g}$ for ${ }^{238} \mathrm{Pu}$ versus $0.062 \mathrm{Ci} / \mathrm{g}$ for ${ }^{239} \mathrm{Pu}$ ). Fleischer and Raabe (1977) measured the size distribution of clustered ${ }^{239} \mathrm{Pu}$ atoms resulting from $\mathrm{PuO}_{2}$ fragmentation by observing fission fragment tracks after neutron activation. They observed that such fragments contained 50 to $10,000{ }^{239} \mathrm{Pu}$ atoms. Fleischer (1975) developed a simple model for the fragmentation (i.e., dissolution) of particles:

$$
\frac{d V}{d t}=\frac{\lambda n V}{4}\left(\frac{\delta}{r}-\frac{\delta^{2}}{r^{2}}+\frac{\delta^{3}}{3 r^{2}}\right),
$$


where

$$
\begin{aligned}
V & =\text { volume of the particle } \\
t & =\text { time } \\
\lambda & =\text { radioactive decay constant } \\
n & =\text { number of atoms ejected per recoil nucleus that leaves the particle, } \\
r & =\text { particle radius, and } \\
\delta & =\text { recoil nucleus range. }
\end{aligned}
$$

For ${ }^{239} \mathrm{Pu}$ decay to ${ }^{235} \mathrm{U}, \delta \sim 200 \AA$. The value of $n$ is estimated to be about $10^{4}$ atoms per decay.

Because they did not observe significant "direct spraying-out of multi-atom fragments" for an experiment that they performed in a dry vacuum system, Fleischer and Raabe (1978) contend that moisture plays a role in the release of aggregate recoils (perhaps by some etching mechanism along the recoil tracks).

Clinard and Rohr (1981) studied fragmentation of $\mathrm{PuO}_{2}$ from the perspective of the potential for the release and leaching of plutonium from waste forms. They observed that ${ }^{238} \mathrm{PuO}_{2}$ undergoes spontaneous fragmentation and that the relatively short-lived ${ }^{238} \mathrm{PuO}_{2}$ is more prone to fragmentation than is ${ }^{239} \mathrm{PuO}_{2}$. For their experiments, Clinard and Rohr prepared samples by hot pressing at $1530^{\circ} \mathrm{C}$ and then firing in an oxidizing atmosphere at $1440^{\circ} \mathrm{C}$. They measured the fragmentation rate of ${ }^{238} \mathrm{Pu}$ samples, which was defined as the rate at which -420 mesh $(<34-\mu \mathrm{m})$ fines were produced. From the data presented, this rate is about $0.001 \%$ /day. Fragmentation was found to continue into submicroscopic particles (i.e., $10-\mu \mathrm{m}$ particles continued to break up). Clinard and Rohr determined by calculation that thermal stresses were not responsible for the fragmentation. They concluded that lattice damage by recoil nuclei and alpha particles, as well as radiolytic effects (e.g., the production of species that attack the lattice) may play a role in fragmentation.

Although the mechanism may not necessarily be fully established, from the experimental work it is clear that in the case of high-specific-activity alpha materials, submicroscopic particles are spontaneously formed. 


\subsection{RESUSPENSION}

Several studies have focused on the release or resuspension of radioactive particles. Such particles can become entrained in air currents and be transported to another location. Coombs and Cuddihy (1983) studied the emanation of ${ }^{232} \mathrm{U}$ - daughter products by recoil and inert-gas diffusion (of radon) from thorium and uranium oxide particles that were doped with $\sim 1 \mathrm{wt} \%{ }^{232} \mathrm{U}$. Recoil daughters were collected on a cathode at $-8000 \mathrm{~V}$, while radon daughters that diffused out of the particles were swept away to a separate chamber where they decayed. The radon daughters that decayed were then collected on another cathode at $-8000 \mathrm{~V}$. Based on calibration data, about $42 \%$ of the recoils were estimated to be collected on the recoil cathode, while $\sim 70 \%$ of the radon daughters were estimated to be collected on the radondaughter cathode. The recoil range of ${ }^{228} \mathrm{Th}$ inside of $\mathrm{UO}_{x}$ and $\mathrm{ThO}_{2}$ particles was reported to be about $17-22 \mu \mathrm{g} / \mathrm{cm}^{2}$. The authors found that about $30 \%$ of the ${ }^{232} \mathrm{U}$ daughters escaped the particle by recoil. About $30-40 \%$ of the ${ }^{220} \mathrm{Rn}$ that formed in the particles escaped by diffusion. While the authors did not mention aggregate recoil, such a phenomenon could certainly contribute to the release that was measured.

Bigu (1991) states that frequent collisions of radioactive aerosols results in their attachment and ultimately in the settling of these particles on surfaces. He lists several mechanisms by which particles may leave a surface: fluid forces, molecular or atomic diffusion, thermal desorption (i.e., off-gassing), electrical desorption (i.e., migration of charged particles under the influence of an electric field), and nuclear recoil. The range of recoiling particles in air resulting from alpha decay with an energy of about $6 \mathrm{MeV}$ is about $0.12 \mathrm{~mm}$ [based on data reported by Mercer (1976) for the recoil of $\mathrm{RaB}\left({ }^{214} \mathrm{~Pb}\right)$ from RaA $\left({ }^{218} \mathrm{Po}\right)$ decay; see Fig. 1]. According to Bigu, desorption by beta recoil is also possible, although not as likely because the recoil energy is much less. However, because some of the early experiments used methods to collect particles that might perturb the measurement (e.g., collection of charged recoil particles by an electric field could lead to electric desorption), one must be careful concerning recoil measurements. Bigu states that for submicron particles, such as radon daughters, airflow-mediated reentrainment of particles from a surface is not a likely desorption mechanism.

Bierman, da Roza, and Chang (1991) performed a theoretical study of the migration of alpha-emitting particles through HEPA filters. Based on this study they developed a numerical model for the resuspension and transport of particles. In this model, nanometer-sized fragments are produced from larger particles by alpha decay (i.e., fragmentation). Fragments migrate through the filter after resuspension by either alpha-recoil or thermal mechanisms. For thermal resuspension, particles that are entrained on filter fibers (or surfaces) receive thermal energy by collisions with passing gas molecules 
and cause these particles to be detached. The recoil energy resulting from alpha decay is sufficient to resuspend nanometer-sized particles from a filter fiber. Particles with densities of $10 \mathrm{~g} / \mathrm{cm}^{3}$ and up to $20 \mathrm{~nm}$ in diameter can be dislodged. While alpha-recoil energy is not sufficient to resuspend micron or submicron particles, fragmentation can lead to the production of even smaller particles that can be resuspended. Bierman, da Roza, and Chang (1991) provide a formulation for the mass percentage release per unit time $(M \%)$ that results from alpha recoil:

$$
M \%=\frac{50 \pi S_{\mathrm{a}} \Delta l r_{\mathrm{f}}^{2} h_{\mathrm{f}} \rho}{d}
$$

where

$$
\begin{aligned}
& S_{\mathrm{a}}=\text { specific activity, } \\
& \Delta l=\text { thickness of the shell about the parent particle from which fragments are released, } \\
& r_{\mathrm{f}}=\text { fragment radius, } \\
& h_{\mathrm{f}}=\text { fragment height, } \\
& \rho \quad=\text { fragment density, and } \\
& d \quad=\text { diameter of the parent particle. }
\end{aligned}
$$

The fragments are assumed to be cone shaped. Table 1 provides estimated fragment release rates for ${ }^{238} \mathrm{PuO}_{2}$ and ${ }^{239} \mathrm{PuO}_{2}$ using the above formulation.

Table 1. Estimated fragment release rates from particles of ${ }^{238} \mathrm{PuO}_{2}$ and ${ }^{239} \mathrm{PuO}_{2}$

\begin{tabular}{lcc}
\hline & Particle and fragment characteristics \\
\hline$\Delta l, \mathrm{~nm}$ & 5 & 2 \\
$r_{\mathrm{f}}, \mathrm{nm}$ & 5 & 2 \\
$h_{\mathrm{f}}, \mathrm{nm}$ & 5 & 2 \\
$d, \mu \mathrm{m}$ & 0.3 & 0.14 \\
${ }^{238} \mathrm{Pu}$ release rate, wt \%/month & 5 & 0.1 \\
${ }^{239} \mathrm{Pu}$ release rate, wt \%/month & 0.02 & 0.0005 \\
Number of molecules per fragment & 3000 & 200 \\
\hline
\end{tabular}


Yamada, Koizumi, and Miyamoto (1999) studied the reentrainment of plutonium particles that had initially been captured on HEPA filter fibers. They prepared source filters by collecting $10^{7}$ to $10^{8} \mathrm{~Bq} / \mathrm{m}^{2}$ of 0.1 - to $0.2-\mu \mathrm{m}{ }^{239} \mathrm{PuO}_{2}$ particles. Experiments lasted for 20 days, and the air velocity and flow pattern were varied for each of the experiments. The dispersion rates [activity of the sampling (or downstream) filter divided by the activity on the source filter and the sampling time] were measured and found to be $2.3 \times 10^{-7} / \mathrm{h}$ for the forward flow direction.

Johnston et al. (1993) studied the resuspension of plutonium and americium particles in an Australian desert. They quantified the resuspension in terms of a "resuspension factor," which is defined as the airborne activity concentration divided by the surface activity density (i.e., activity per unit area). The studies were performed over a 1-year period, and an average resuspension factor of $4 \times 10^{-10} \mathrm{~m}^{-1}$ was measured. The resuspension can increase by up to 3 orders of magnitude for winds greater than $10 \mathrm{~m} / \mathrm{s}$. The authors did not assess the effects of alpha recoil on resuspension. However, they do assume that only particles less than $75 \mu \mathrm{m}$ can be resuspended. Therefore, fragmentation by alpha recoil can increase the amount of material available for resuspension.

Leonard (1995) made measurements of the resuspension of ${ }^{222} \mathrm{Rn}$ particulate progeny from residential materials. In this case, Leonard defined a resuspension factor (different from that above) as the fraction of plated-out atoms (e.g., ${ }^{218} \mathrm{Po}$ and ${ }^{214} \mathrm{~Pb}$ ) whose progeny become resuspended upon radioactive decay (i.e., by alpha recoil of the progeny). Measurements were performed in a closed, environmentallycontrolled test chamber - with typical residential temperature and airflow rates - using a number of different residential materials as the plating-out surface. The measured resuspension factors for ${ }^{214} \mathrm{~Pb}$ recoil ranged from 0.29 to 0.55 .

\subsection{SRS EXPERIENCE WITH ${ }^{238} \mathrm{Pu}$}

A description of the SRS experience with high-mobility ${ }^{238} \mathrm{PuO}_{2}$ particles is provided by Congdon (1996). Plutonium-238 was produced in SRS reactors and separated in the HB-line canyon building. Initially, pellets were fabricated at Mound, then at the Plutonium Fuel Fabrication Facility (PuFF) at SRS, and finally at Los Alamos National Laboratory (LANL). The following discussion details the experience at the SRS PuFF facility.

Plutonium oxalate was produced from the SRS separations process. The subsequent calcination of the oxalate resulted in 5- to 10 - $\mu \mathrm{m}$-sized particles. The material was further ball milled, creating particles less than $2 \mu \mathrm{m}$, with a significant fraction in the submicron range. (Note: Materials at LANL are still 
prepared in a similar manner.) Fines were generated by a number of steps that were performed during pellet processing: ball milling, sieving, mixing, and sectioning of pellets for metallographic analysis.

Congdon (1996) described significant evidence of high ${ }^{238} \mathrm{Pu}$ mobility. The number of contamination incidents involving ${ }^{238} \mathrm{Pu}$ was 3.5 times those for ${ }^{239} \mathrm{Pu}$. However, more than 100 times the quantity of ${ }^{239} \mathrm{Pu}$ was processed. The incident rate is close to the ratio of the specific activities and the amount of material processed [i.e., $(17 \mathrm{Ci} / \mathrm{g}) \times 1 \mathrm{~g} /(0.062 \mathrm{Ci} / \mathrm{g}) \times 100 \mathrm{~g}=2.7$ ]. Clearly, the ${ }^{238} \mathrm{Pu}$ was more difficult to control and contain than the ${ }^{239} \mathrm{Pu}$. Personnel involved with processing ${ }^{238} \mathrm{Pu}$ indicated that it had "lifelike" characteristics, as the fines appeared to "fly" through the air or "walk" along pipes. Congdon states that "in some cases, the fine particles appear to behave more like a gas than a solid." Additionally, "alpha decay and heat cause numerous failures of 35 mil thick rubber gloves," even in a matter of days. When ${ }^{238} \mathrm{Pu}$ particles got outside of containment, they sometimes traveled for hundreds of feet, rather than directly settling. According to Congdon, "other types of radioactive materials do not appear to be nearly as mobile as ${ }^{238} \mathrm{Pu}$ and are usually spread by physically spreading the material from one surface to another." Such surfaces were difficult to decontaminate. Fine particles of ${ }^{238} \mathrm{Pu}$ were easily dispersed (resuspended) into the air, and previously decontaminated surfaces were found to be recontaminated after several hours or days. Because of self-heating, ${ }^{238} \mathrm{Pu}$ oxide does not tend to absorb water. Furthermore, ${ }^{238} \mathrm{Pu}$ tends to remain as individual particles rather than forming agglomerates. (Note that one cause of agglomeration would be adsorption of water, thereby causing the particles to stick together.) Additionally, alpha emissions and the concomitant recoil may act to break up agglomerates. Such small particles are then easily dispersed, especially since the dry ${ }^{238} \mathrm{Pu}$ particles do not adhere to surfaces. A recent assessment of the contamination problem and the mobility of ${ }^{238} \mathrm{Pu}$ particles is also provided by Reichel (2004).

\section{DISCUSSION}

The experience with ${ }^{238} \mathrm{Pu}$ reported at SRS is a clear example of the high mobility (and containment difficulty) of high-specific-activity alpha-emitting radionuclides. Such characteristics often dictate processing requirements for these materials. For example, the processing of ${ }^{244} \mathrm{Cm}$ and ${ }^{252} \mathrm{Cf}$ at the Oak Ridge National Laboratory (ORNL) is performed in the liquid phase as much as practical. Powders are produced only when absolutely necessary. Such a philosophy has been carried into recent design efforts 
by ORNL for ${ }^{238} \mathrm{Pu}$ processing. In this case, the handling of highly dispersable powders is avoided until the production of the final material for shipment.

A large body of evidence exists that describes the movement of high-specific-activity alpha material. This movement has been quantified by a number of methods. Releases have been reported in terms of a transfer rate constant, $K_{S}$, with values given for the isotopes ${ }^{238} \mathrm{Pu},{ }^{253} \mathrm{Es}$, and ${ }^{212} \mathrm{~Pb}$. These rate constants can be used to calculate the rate of release of atoms from a source by aggregate recoil. The number of atoms released per recoil atom ranges from 50 to 10,000 .

The movement of particles has also been described in terms of fragmentation. Models have been developed that describe the rate of fragmentation (and, hence, the rate of production of smaller particles). The fragmentation rate of ${ }^{238} \mathrm{Pu}$ has been measured to be $\sim 0.001 \%$ /day (to produce $<34-\mu \mathrm{m}$ fines).

The resuspension of alpha-active particles has been quantified by a number of techniques. Estimates of the mass percentage release by alpha recoil for ${ }^{238} \mathrm{PuO}_{2}$ range from 0.1 to $5 \mathrm{wt} \%$ per month, with 200 to 3000 molecules per fragment. Another method used to quantify resuspension is the dispersion rate, which is the activity deposited on a filter that is downstream from a source filter divided by the source activity and the sampling time. This idea can be extended to the activity released per unit time per unit source activity. The dispersion rate for ${ }^{239} \mathrm{PuO}_{2}$ has been measured to be $2.3 \times 10^{-7} / \mathrm{h}$. Finally, resuspension factors have been measured to quantify the fraction of a source that becomes airborne. Two different types of resuspension factors have been described in the literature. The first is the ratio of the airborne concentration divided by the surface activity density. An average value of $4 \times 10^{-10} \mathrm{~m}^{-1}$ was measured for plutonium and americium isotopes in a desert environment. However, this value was very sensitive to the wind speed - increasing by up to 3 orders of magnitude for winds $>10 \mathrm{~m} / \mathrm{s}$. Another form of the resuspension factor is defined as the fraction of plated-out atoms whose progeny become resuspended. For studies with radon in a residential environment, resuspension of 29 to $55 \%$ of the plated-out atoms has been measured.

The foregoing discussion illustrates the variety of methods used to measure the movement of radionuclides by alpha recoil. In the context of modeling the transport of radionuclides, the contribution of alpha recoil (e.g., resuspension of particulates) could be incorporated into environmental models. Depending on the details of the particular model, quantities such as transfer rates, fragmentation rates, dispersion rates, and resuspension factors can be used to quantify the rate of production, size, and release of active particles from a source on which they are deposited. Certainly, there are limited data available on these quantities for a small number of nuclides. In the absence of additional data, reasonable estimates can be made for other radionuclides on the basis of specific activity, decay energy, and density of 
materials. To further quantify the movement and dispersion of initial deposits of high-specific-activity alpha materials, experiments have been designed at ORNL to measure such movement.

When making decisions about containment strategies for radioactive materials, the special characteristics of the high-specific-activity alpha-emitting radionuclides must be considered, in particular. In the case of a deposit of such material, a factor to consider is where to set the boundaries because of alpha mobility and for the protection of responding personnel. The fragmentation of these particles can increase the concentration of respirable particles with time. Additionally, the recoil of aggregates, combined with increasingly small aggregate sizes, can lead to resuspension and further airborne transport. Finally, these characteristics make filtration of these materials difficult and therefore close monitoring of personnel is required to prevent uptake in a cleanup or repose situation.

\section{CONCLUSION}

This report describes the results of an extensive survey of the literature with regard to alpha-recoil transport. While specific citations used in the text of the report are listed in the reference section within the body of the report, an appendix has also been included to list all the relevant literature consulted during the course of this review.

Alpha decay can result in the fragmentation of particles into smaller respirable fractions. Additionally, recoil nuclei can cause the movement or resuspension of radioactive material. Such movement must be considered when modeling the release of such material. Studies, especially with filtration media, have shown that the effects of aggregate recoil transport should be considered in response to and cleanup of release events. Aggregate recoil increases the penetration of filtration media, thereby lowering its effectiveness. 


\section{REFERENCES}

Bierman, A. H., R. A. da Roza, and Y. Chang (1991). Alpha Migration Through Air Filters: A Numerical Simulation, UCRL-LR-109866, Lawrence Livermore National Laboratory, University of California, Livermore, California.

Bigu, J. (1991). "Desorption of ${ }^{220}$ Rn Progeny from Large Surfaces by $\alpha$ - and $\beta$ - Recoil Processes," Health Phys. 61(2), 215-224.

Clinard, F. W., and D. L. Rohr (1981). "Spontaneous Fragmentation of an Alpha-Active Ceramic-A Mechanism for Dispersion of Solid Waste?" pp. 405-412 in Scientific Basis for Nuclear Waste Management, Vol. 3, Plenum Press, New York.

Congdon, J. W. (1996). "Physical Behavior of Pu-238 Oxide," SRT-MTS-96-3026, Westinghouse Savannah River Company, Aiken, South Carolina, letter to J. Herzog, Lockheed Idaho Technology Co., Idaho Falls, Idaho, October 17.

Coombs, M. A. and R. G. Cuddihy (1983). "Emanation of ${ }^{232}$ U Daughter Products from Submicrometer Particles of Uranium Oxide and Thorium Dioxide by Nuclear Recoil and Inert Gas Diffusion," J. Aerosol Sci., 14:2, pp. 75-86.

Fleischer, R. L. (1975). “On the 'Dissolution' of Respirable $\mathrm{PuO}_{2}$ Particles," Health Phys. 29 69-73.

Fleischer, R. L., and O. G. Raabe (1977). "Fragmentation of Respirable $\mathrm{PuO}_{2}$ Particles in Water by Alpha Decay-A Mode of 'Dissolution,'” Health Phys. 32, 253-257.

Fleischer, R. L., and O. G. Raabe (1978). "On the Mechanism of 'Dissolution' in Liquids of $\mathrm{PuO}_{2}$ by Alpha Decay," Health Phys. 35, 545-548.

Harrington, E. L. (1928). "Experimental Evidence on the Existence of Aggregates of Active Deposit Atoms in Gases Containing Radon," Philos. Mag. 6, 685-695.

Harrington, E. L., and O. A. Gratias (1931). "The Formation of Molecular Aggregates in Radon-Gas Mixtures Containing Polar Molecules,” Philos. Mag. 11, 285-296.

Johnston, P. N., G. A. Williams, P. A. Burns, and M. B. Cooper (1993). "Plutonium Resuspension and Airborne Dust Loadings in Desert Environment of Maralinga, South Australia," J. Environ. Radioactiv. 20, 117-131.

Lawson, R. W. (1919). “The Aggregate Recoil of Radio-active Substances Emitting a-Rays," Nature 102(2572), 464-465 (February 13).

Lawson, R. W. (1924). “The Anomalous Emission of a-Particles from Polonium,” Nature 114(2856), 121-122 (July 26). 
Leonard, B. E. (1995). “2222Rn Progeny Surface Deposition and Resuspension—Residential Materials,” Health Phys. 69(1), 75-92.

Makower, W., and S. Russ (1910). "The Recoil of Radium C from Radium B,” Philos. Mag. 19, 100.

McDowell, W. J., F. G. Seeley, and M. T. Ryan (1976). "Penetration of HEPA-Filters by Alpha Recoil Aerosols," pp. 662-676 in Proceedings of the Fourteenth ERDA Air Cleaning Conference, Sun Valley, Idaho, CONF-760822-P2, Energy Research and Development Administration, Washington, D.C.

McDowell, W. J., F. G. Seeley, and M. T. Ryan (1977). "Penetration of HEPA-Filters by Alpha Recoil Aerosols," Health Phys. 32, 445-447.

Mercer, T. T. (1976). "The Effect of Particle Size on the Escape of Recoiling RaB Atoms from Particulate Surfaces," Health Phys. 31, 173-175.

Reichel, R. (2004). Building 235-F Legacy Source Term Feasibility Study, Appendix B, G-ESR-F-00036, Savannah River Site, Aiken, South Carolina, September 15

Rutherford, E., J. Chadwick, and C. D. Ellis (1930). Radiations from Radioactive Substances, Cambridge University Press, London, pp. 557-558.

Ryan, M. T., W. J. McDowell, and G. N. Case (1977). Observations on the Distribution and the Nature of Alpha-Active Particulate Material in a HEPA Filter Used for Plutonium-Containing Dust, ORNL/TM5765, Oak Ridge National Laboratory, Oak Ridge, Tennessee.

Ryan, M. T., K. W. Skrable, and G. Chabot (1975). "Retention and Penetration Characteristics of a Glass Fiber Filter for ${ }^{212} \mathrm{~Pb}$ Aggregate Recoil Particles," Health Phys. 29, 796-798.

Yamada, Y., A. Koizumi, and K. Miyamoto (1999). "Re-entrainment of ${ }^{239} \mathrm{PuO}_{2}$ Particles Captured on HEPA Filter Fibers," Radiat. Protect. Dosim. 82(1), 25-29. 



\section{APPENDIX. BIBLIOGRAPHY OF SOURCES REVIEWED}

The following articles were consulted in the course of this review. While a particular article may not have been specifically cited in this report, in many instances phenomena relevant to alpha recoil transport are described.

\begin{tabular}{|c|c|c|}
\hline Author(s) & Reference & Date \\
\hline $\begin{array}{l}\text { Makower, W.; } \\
\text { Russ, S. }\end{array}$ & "The recoil of Radium C from Radium B," Phil. Mag. 19, p. 100. & 1910 \\
\hline Ratner, S. & $\begin{array}{l}\text { "On Some Properties of the Active Deposit of Radium," Phil. Mag. } \\
\text { 36, p. } 397 .\end{array}$ & 1918 \\
\hline Lawson, R.W. & $\begin{array}{l}\text { "Reflection of particles in long tubes," Akad. Wiss. Wien. Ber.,127, } \\
\text { IIA, pp. 535-562. }\end{array}$ & 1918 \\
\hline Lawson, R.W. & $\begin{array}{l}\text { Letter to Nature, references to paper nos. } 80 \text { and } 113 \text { from the } \\
\text { Vienna Radium Institute. }\end{array}$ & 1919 \\
\hline Lawson, R.W. & $\begin{array}{l}\text { "Aggregate recoil accompanying the decay of substances emitting } \alpha \text { - } \\
\text { rays," Sitzb. Akad. Wiss, Wien. 18(IIa), pp. 795-830. }\end{array}$ & 1920 \\
\hline Lawson, R.W. & $\begin{array}{l}\text { "The anomalous emission of } \alpha \text {-particles from polonium," Nature, } \\
\text { p. } 114 .\end{array}$ & 1924 \\
\hline Harrington, E.L. & $\begin{array}{l}\text { "Experimental Evidence of the Existence of Aggregates of Active } \\
\text { Deposit Atoms in Gases Containing Radon," Phil. Mag. 6, p. } 685 \text {. }\end{array}$ & 1928 \\
\hline $\begin{array}{l}\text { Rutherford, E.; } \\
\text { Chadwick, J.; } \\
\text { Ellis, C.D. }\end{array}$ & $\begin{array}{l}\text { "Radiation from Radioactive Substances," Cambridge University } \\
\text { Press, London, pp. 557-558. }\end{array}$ & 1930 \\
\hline $\begin{array}{l}\text { Harrington, E.L.; } \\
\text { Gratuas, O.A. }\end{array}$ & $\begin{array}{l}\text { "The Formation of Molecular Aggregates in Radon-Gas Mixtures } \\
\text { Containing Polar Molecules," Phil. Mag. 11, p. } 285 .\end{array}$ & 1931 \\
\hline $\begin{array}{l}\text { Harrington, E.L.; } \\
\text { Braaten, E. O. }\end{array}$ & $\begin{array}{l}\text { "Mobilities of Molecular Aggregates in Gases Containing Radon," } \\
\text { Trans. Roy. Soc. Can. III, 26, 177-86. }\end{array}$ & 1932 \\
\hline Chamie, C. & $\begin{array}{l}\text { "Sur la diffusion du recul radioative, " J. Phys Radium, Paris 5, } \\
\text { p. } 436 .\end{array}$ & 1934 \\
\hline $\begin{array}{l}\text { Ermilov, A.P.; } \\
\text { Klinov, V.V.; } \\
\text { Labushkin, V.G. }\end{array}$ & $\begin{array}{l}\text { "On Behavior of Ra Daughter Products in Air," At. Energ.(Russia), } \\
\text { 25, pp. 61-2. (Full paper published as "Effects of walls on the } \\
\text { concentration distribution of free RaA and RaB atoms in an enclosed } \\
\text { air space," Soviet Atomic Energy, 25, pp. 803-805.) }\end{array}$ & 1968 \\
\hline
\end{tabular}


Ryan, M. T.; "Retention and Penetration Characteristics of a Glass Fiber Filter for

Skrable, K. W.; $\quad{ }^{212} \mathrm{~Pb}$ Aggregate Recoil Particles," Health Physics 29,

Chabot, G. pp. 796-798.

Fleischer, R. L. “On the 'Dissolution' of Respirable $\mathrm{PuO}_{2}$ Particles,” Health Physics, 29, pp. 69-73.

1975

Jonassen, N.; $\quad$ "On the Recoil of RaB from Membrane Filters," J. Aerosol Sci. 7,

1976

McLaughlin, J.P. pp. 141-149.

Mercer, T.T. "The effect of particle size on the escape of recoiling RaB atoms from particulate surfaces," Health Physics, 31, pp. 173-175.

McDowell, W.J.; "Penetration of HEPA filters by alpha recoil aerosols," Proceedings

Seeley, F.G.; of the fourteenth ERDA air cleaning conference,

Ryan, M.T. $\quad$ pp. 662-676, Sun Valley, ID (August).

McDowell, W.J.; "Penetration of HEPA-filters by Alpha Recoil Aerosols," Health

Seeley, F.G.; $\quad$ Physics 32, pp. 445-447.

Ryan, M.T.

Ryan, M.T.; $\quad$ Observations of the Distribution and Nature of Alpha-Active

McDowell, W.J.; $\quad$ Particulate Material in a HEPA Filter Used for Plutonium-

Case, G.N. $\quad$ containing Dust, Oak Ridge National Laboratory Report, ORNL/TM-5765 (February).

Fleischer, R. L.; "Fragmentation of Respirable $\mathrm{PuO}_{2}$ Particles in Water by Alpha

Raabe, O.G. $\quad$ Decay -- a Mode of 'Dissolution'," Health Physics, 32, p. 253.

1977

Fleischer, R.L.; 'On the Mechanism of 'Dissolution' in Liquids of $\mathrm{PuO}_{2}$ by Alpha

Raabe, O.G. $\quad$ Decay," Health Physics, 35, p. 545.

1978

Fleischer, R. L. "Recoiling alpha-emitting nuclei. Mechanisms for uranium-series

1978 disequilibrium," Geochim. Cosmochim. Acta. 42, pp. 973-978.

Clinard, F. W.; $\quad$ "Spontaneous Fragmentation of an Alpha-Active Ceramic - A

1981

Rohr, D. L.

Mechanism for Dispersion of Solid Waste?," Scientific Basis for Nuclear Waste Management, Vol 3, pp. 405-412.

Fleischer, R.L. "Theory of Alpha Recoil Effects on Radon Release and Isotopic

Coombs, M.A.; "Emanation of ${ }^{232}$ U Daughter Products from Submicrometer Particles Cuddihy, R.G. of Uranium Oxide and Thorium Dioxide by Nuclear Recoil and Inert 1983 Gas Diffusion," J. Aerosol Sci., 14:2, pp. 75-86. 
RAMA; Moore, "Mechanism of Transport of U-Th Series Radioisotopes from Solids

Rudnick, S.N.; "Surface Deposition of ${ }^{222}$ Rn Decay Products with and without

Mewhinney, J.A. Radiation Dose Estimates and Hazard Evaluations for Inhaled Airborne Radionuclide, NUREG/CR-4986 RH, Lovelace Biomedical and Environmental Research Institute, Albuquerque, NM for US NRC.

Hopke, P.K.; “The Initial Behaviour of ${ }^{218}$ Po in Indoor Air," Radiation Protection

Kulju, L.M.;

Ramamurthi, M.

Bunzl, K.; Kracke, W.

Wen, H.Y.; Kasper, G.

Biermann, A.H.; da Roza, R.A.; Chang, Yun

Bigu, J.

Adloff, J.P.; Roessler, K.

Johnston, P.N.; Williams, G.A.; Burns, P.A.; Cooper, M.B.

Baugues, C.M.; Chyi, L.L.
"Cumulative Deposition of ${ }^{137} \mathrm{Cs},{ }^{238} \mathrm{Pu},{ }^{239+240} \mathrm{Pu}$ and ${ }^{241} \mathrm{Am}$ from Global Fallout in Soils from Forest, Grassland and Arable Land in Bavaria (FRG)," J. Environmental Radioactivity 8(1), pp. 1-14.

"On the Kinetics of Particle Reentrainment form Surfaces," $J$. Aerosol Sci. 20, pp. 483-498.

Alpha migration through air filters: A numerical simulation, Lawrence Livermore National Laboratory.

"Desorption of ${ }^{220} \mathrm{Rn}$ Progeny from Large Surfaces by $\alpha$ - and $\beta$-recoil Processes," Health Phys. 61, pp. 215-224.

"Recoil and Transmutation Effects in the Migration Behaviour of Actinides," Radiochimica Acta, 52/53 pt 1, pp. 269-274.

"Plutonium Resuspension and Airborne Dust Loadings in the Desert Environment of Maralinga, South Australia," Journal of Environmental Radioactivity 20, pp. 117-131.

"New observations in radon emanation and migration," Geological 1993 
Piper, H.B.; $\quad$ Type B investigation of the iridium contamination event at the High

Cheverton, R.D.; $\quad$ Flux Isotope Reactor September 7, 1993, ORNL/M-3175, DOE/OR-

Hamley, S.A.; 2004 (March).

Hill, J.P.; Lee,

T.B.

Mayya, Y.S.;

"Studies on the diffusional electrical transport of the daughter

1994

Sahni, D.C. aerosols of radon and thoron in moving gases," Bhabha Atomic Research Centre, Bombay, India.

Leonard, B.E. $\quad{ }^{6222} \mathrm{Rn}$ Progeny Surface-Deposition and Resuspension- Residential

Tcherkezian, V.; $\quad$ "Forms of contamination of the environment by radionuclides after

\section{Galushkin, B.; $\quad$ the Tomsk accident (Russia 1993)," J. of Environmental}

Goryachenkova, Radioactivity 27, 133-139.

T.; Kashkarov,

L.; Liul, A.;

Roschina, I.; and

Rumiantsev, O.

Manjon, G.; "The Presence of Man-made Radionuclides in the Marine

Garcia-Leon, M.; Environment in the South of Spain," J. of Environmental

Ballestra, S.; Radioactivity 28(2), pp.171-189.

Lopez, J.J.

Congdon, J. W. Physical Behavior of Pu-238 Oxide, Savannah River Site, SRTMTS-96-3026 (October 17).

El-Hussein, A. "Unattached Fractions, Attachment and Deposition Rates of Radon Progeny in Indoor Air," Appl. Radiat, Isot. 47 (5/6), pp. 515-523.

Gasco, C.; "Influence of the submarine orography on the distribution of long-

Anton, M.. $\quad$ lived radionuclides in the Palomares marine ecosystem," $J$.

Environmental Radioactivity 34(2), pp. 111-125.

Yamada, Y.; "Re-Entrainment of ${ }^{239} \mathrm{PuO}^{2}$ Particles Captured on Hepa Filter

Koizumi, A.; $\quad$ Fibres," Radiation Protection Dosimetry 82:1. pp. 25-29.

Miyamoto, K.

Fleischer, R. L. "Etching of recoil tracks in solids," Geochimica et Cosmochimica Acta, 67(24), pp. 4769-4774.

Reichel, R. $\quad$ Appendix B, Properties of Pu-238 Oxide, from Building 235-F Legacy Source Term Feasibility Study, G-ESR-F-00036 Rev. 0, Savannah River Site (September 14). 
ORNL/TM-2005/22

\section{INTERNAL DISTRIBUTION}

$\begin{aligned} \text { 1. } & \text { W. S. Aaron } \\ \text { 2. } & \text { J. F. Birdwell } \\ \text { 3. } & \text { R. M. Counce } \\ \text { 4. } & \text { D. W. DePaoli } \\ \text { 5. } & \text { L. K. Felker } \\ 6 . & \text { M. Ferren } \\ \text { 7-10. } & \text { A. S. Icenhour } \\ \text { 11. } & \text { H. L. Jennings } \\ \text { 12. } & \text { R. T. Jubin } \\ \text { 13. } & \text { B. E. Lewis }\end{aligned}$

14. J. McFarlane

15. B. D. Patton

16. J. E. Rushton

17. A. L. Sjoreen

18. R. D. Spence

19. B. B. Spencer

20. M. S. Spurlin

21. R. M. Wham

22. J. D. White

23. NSTD DMC

24. ORNL OTIC-RC, OSTI, CRL

\section{EXTERNAL DISTRIBUTION}

25. M. Carter, U.S. Department of Homeland Security, Washington, DC 20528

26. T. Fainberg, U.S. Department of Homeland Security, Washington, DC 20528

27. F. T. Harper, Sandia National Laboratories - New Mexico, P.O. Box 5800, Albuquerque, NM 87185-0791

28. T. Kiess, U.S. Department of Homeland Security, Washington, DC 20528

29. E. Smith, Westinghouse Savannah River Site, Bldg 730-4B, Rte. 1A, Aiken, SC 